\title{
Mineralized Peptide Nanofiber Gels for Enhanced Osteogenic Differentiation
}

\author{
E. Deniz Eren ${ }^{+},{ }^{[a, b]}$ Gulistan Tansik $^{+},{ }^{[a]}$ Ayse B. Tekinay, ${ }^{*[a]}$ and Mustafa O. Guler ${ }^{*[c]}$
}

\begin{abstract}
Mineral deposition is observed in both bacterial and eukaryotic organisms through a broad range of mechanisms. Both organic and inorganic components play crucial roles in the formation of mineralized tissues, and acidic proteins are particularly important in this context owing to their ability to stimulate nucleation of minerals. Here, we present negatively-charged self-assembling peptide amphiphile molecules as a template to nucleate calcium phosphate mineralization in a bioactive scaffold environment. Acidic peptide molecules were shown to induce formation of
\end{abstract}

hydroxyapatite like calcium phosphate mineralization, which was characterized by scanning electron microscopy, transmission electron microscopy, thermogravimetric analysis, $\mathrm{X}$ ray diffractometry, oscillatory rheology and atomic force microscopy. The osteoblast-like cells were found to reveal enhanced osteogenic differentiation on pre-mineralized peptide nanofiber networks, suggesting that mineral deposition can be used as a means of enhancing the bioactivity of peptide-based scaffold systems.

\section{Introduction}

In nature, organisms produce a diverse range of highly specialized organic-inorganic hybrid composite materials and utilize them in various life processes such as mussel attachment, predator defense and protection against environmental stress. ${ }^{[1]}$ Calcium phosphate-containing structures are found in vertebrate bones and teeth and exist in different compositions depending on factors such as tissue type, location, age, injury status and diet. $^{[2]}$ Mineral deposition in these structures is regulated through the nucleating action of negatively-charged proteins such as osteonectin, type-I collagen, bone sialoprotein and osteocalcin, which allow the formation of well-ordered hydroxyapatite crystals under mild environmental conditions. ${ }^{[3]}$ In addition to mediating the process of mineral deposition through template-directed nucleation, these proteins also serve as structural elements in teeth and bones; for example, hydroxyapatite and type I collagen are known to create a hybrid structure that imparts bone tissue with its characteristic tolerance to external stress. ${ }^{[4]}$

[a] E. D. Eren, ${ }^{+}$Dr. G. Tansik, ${ }^{+}$Prof. A. B. Tekinay

Institute of Materials Science and Nanotechnology, National Nanotechnology Research Center (UNAM), Bilkent University, Ankara, Turkey, 06800 E-mail: atekinay@bilkent.edu.tr

[b] E. D. Eren ${ }^{+}$

Department of Chemical Engineering and Chemistry, Eindhoven University of Technology, MB, Eindhoven, The Netherlands

[c] Prof. M. O. Guler

Institute for Molecular Engineering, University of Chicago, Chicago, IL, 60637, USA

E-mail: mguler@uchicago.edu

$\left.{ }^{+}\right]$These authors contributed equally to this work.

$\square$ Supporting information for this article is available on the WWW under https://doi.org/10.1002/cnma.201700354

This manuscript is part of a Special Issue on Supramolecular Nanostructures. Click here to see the Table of Contents of the special issue.
Fabrication of organic-inorganic hybrid materials through controlled mineralization processes similar to those present in nature has become an important aspect of regenerative medicine, as these structures can provide further insight into the mechanisms of the biomineralization and assist in the development of more effective biomimetic materials..$^{[5]}$ In order to produce synthetic composite materials incorporating both the organic and inorganic components of the native bone tissue, several studies have utilized organic template mineralization processes that emulate several features of natural biomineralization. ${ }^{[6]}$ In particular, phosphoserine-rich motifs present in dentin proteins have been mimicked using a peptide amphiphile (PA) system that serves as a template for the deposition of hydroxyapatite crystals..$^{[6,7]}$ These materials were incorporated into load-bearing metallic materials to repair fractures, rebuild joints and replace teeth through the effective integration of the implant with the surrounding mineral matrix.

Peptide amphiphile (PA) molecules combine the structural properties of amphiphilic surfactants with the bioactive peptides. They received a considerable interest not only because they are biocompatible and biodegradable but also they have unique nanostructured features. ${ }^{[8]}$ We have previously shown that nanofibers functionalized by Glu-Glu-Glu (EEE) sequence enhanced biomineralization process due to osteoinductive properties for differentiation of mesenchymal stem cells. ${ }^{[9]}$ In this work, we report design and fabrication of a mineralized peptide nanofiber composite gel that can potentially be employed in biomineralization applications. A negativelycharged PA molecule was used to emulate the charge-mediated mineralization process that occurs in bones and teeth, and a mineral precursor solution $\left(\mathrm{CaCl}_{2}\right)$ was used prior to mineralization to trigger the self-assembly of the PA molecules. The $\left(\mathrm{NH}_{4}\right)_{2}$ $\mathrm{HPO}_{4}$ was then used to facilitate the growth and formation of calcium phosphate biominerals on the peptide nanofiber 
scaffold template. The PA nanofiber gel formation and biomineralization process were investigated by scanning electron microscopy (SEM), transmission electron microscopy (TEM), thermogravimetric analysis (TGA), X-ray diffraction (XRD), oscillatory rheology and atomic force microscopy (AFM). The mineralization of the peptide nanofiber gel was confirmed through spectroscopic analyses and was found to enhance the mechanical stiffness of the system. In addition, we investigated the osteogenic differentiation of osteoblast-like cells on hydroxyapatite coated peptide nanofibers to determine the potential applications of this biomineralized scaffold in regenerative medicine. In 14 days, osteoblast-like cells on hydroxyapatite coated peptide nanofibers exhibited a higher alkaline phosphatase (ALP) activity and increased mRNA expression of Runx2, Collagen I and osteocalcin compared to cells on non-mineralized peptide nanofibers and uncoated tissue culture plate (TCP), suggesting that mineralization-inducing peptide materials could serve as effective promoters of osteogenesis.

\section{Results and Discussion}

\section{Mineralized Peptide Nanofiber Gel Preparation and Characterization}

The $\mathrm{E}_{3}$-PA molecule was designed and synthesized to mimic the negatively-charged residues of template proteins that regulate the biomineralization process, and was used for formation of a negatively-charged peptide nanofiber scaffold (Figure S1). ${ }^{[10]}$ The PA molecules consist of a hydrophilic and a hydrophobic domain and can self-assemble into nanofibers. ${ }^{[11]}$ Noncovalent intermolecular interactions play a crucial role for triggering and stabilizing nanofiber formation, and also regulate bulk physical properties of the resulting nanofiber network such as the mechanical integrity of the gels. Nanofiber formation triggered by $\mathrm{Ca}^{2+}$ ions results in more stable and mechanically superior gels compared to gels formed by $\mathrm{H}^{+}$ions. ${ }^{[11, \mathrm{~d}, 12]}$ In addition, templated mineral growth can be achieved through $\mathrm{Ca}^{2+}$ iondirected nanofiber formation. ${ }^{[6 b]}$ Here $\mathrm{CaCl}_{2}$ was used to trigger the self-assembly of PA molecules through charge neutralization (Scheme 1) and $\left(\mathrm{NH}_{4}\right)_{2} \mathrm{HPO}_{4}$ solution was added for the
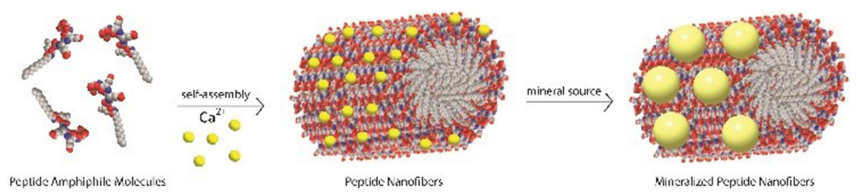

Scheme 1. Schematic representation of the formation of mineralized peptide nanofibers.

nucleation of calcium phosphate minerals on the surface of the nanofibers.

Nucleation of minerals on the peptide nanofibers were observed after allowing the phosphate buffer to interact with $\mathrm{Ca}^{2+}$ ion-decorated peptide nanofibers for $30 \mathrm{~min}$ (Figures $1 \mathrm{a}$ and $1 \mathrm{~b})$. Nucleation and growth of biominerals were also
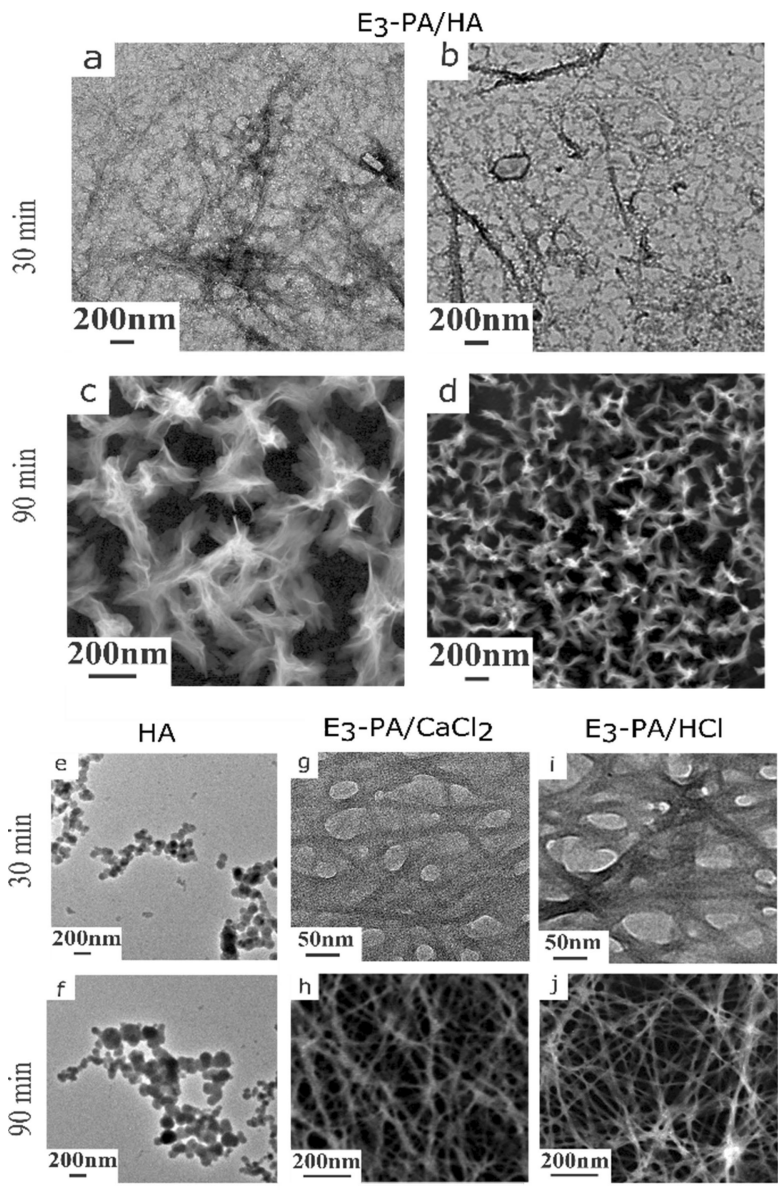

Figure 1. Calcium phosphate mineralization induced by the peptide nanofiber morphology. $(a, b)$ Calcium phosphate mineralization after 30 min of exposure; $(c, d)$ plate-like hydroxyapatite (HA) crystal formation after 90 min of calcium phosphate mineralization; ( $e, f$ ) randomly distributed calcium phosphate mineralization in the absence of $E_{3}-P A$ and $(g, h, i, j)$ nonmineralized scaffolds.

observed in the absence of $\mathrm{E}_{3}$-PA after $30 \mathrm{~min}$, but the minerals formed in a random fashion and their size was not controlled (Figure 1e). Following mineralization for $90 \mathrm{~min}$, plate-like crystals were observed to grow on peptide nanofibers, which indicated the formation of hydroxyapatite minerals on the template material ${ }^{[13]}$ (Figures $1 \mathrm{c}$ and $1 \mathrm{~d}$ ). In contrast, template effect was not observed even after 90 min of incubation in the absence of the peptide molecules (Figure 1f). The nanofiberinduced templating effect is attributed to the influence of $\mathrm{Ca}^{2+}$ ions that promote the formation of nanofibers by chelating the glutamic acid residues on the surface (Figures $1 \mathrm{~g}$ and $1 \mathrm{~h}$ ).

AFM was used to analyze the morphology of the mineralized and non-mineralized peptide nanofibers (Figure S2a and $\mathrm{S} 2 \mathrm{~b}$ ). While the formation of minerals was observed clearly in mineralized gel systems, non-mineralized $E_{3}-P A$ system showed no mineral content. SEM was used to study the effect of minerals on the morphology of peptide nanofibers, and template effect of $E_{3}-P A$ was clearly observed by the SEM images (Figures $2 a$ and $2 b$ ). However, when $E_{3}-P A$ was not used, random distribution of calcium phosphate mineral was obtained due to the absence of glutamate residues (Figures $2 c$ 

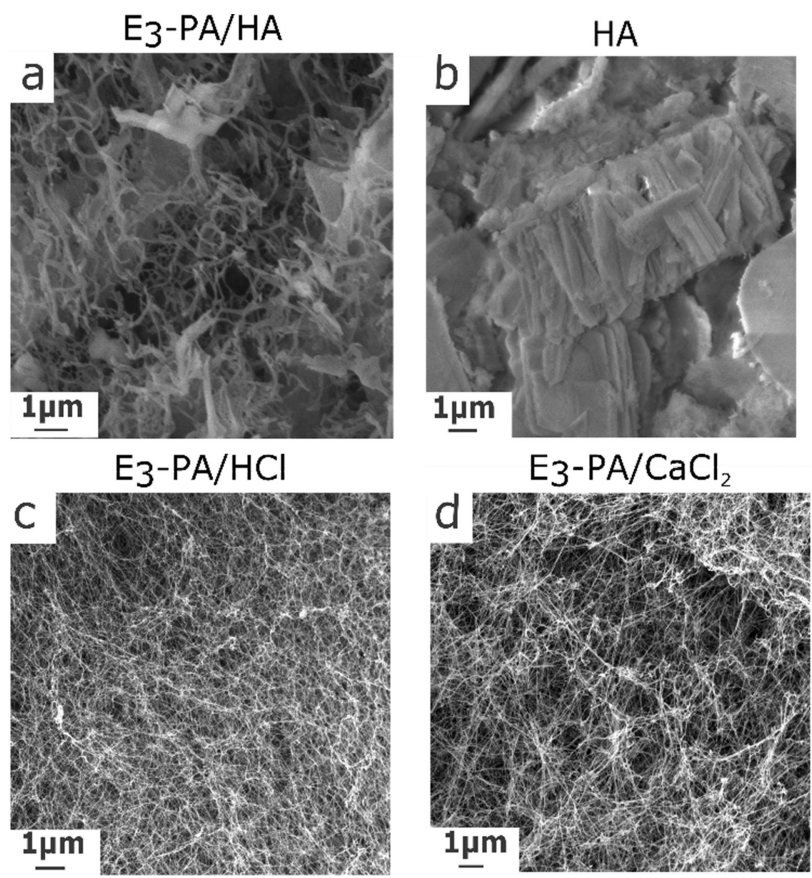

Figure 2. SEM images of (a) hydroxyapatite like calcium phosphate (HA) mineralized peptide amphiphile nanofibers after $24 \mathrm{~h}$ of incubation, (b) calcium phosphate mineralization in the absence of $E_{3}-P A$, and $(c, d)$ nonmineralized scaffolds.

and $2 \mathrm{~d}$ ). The SEM images also revealed the porous structure of the mineralized peptide nanofiber network after $24 \mathrm{~h}$, which is a characteristic of scaffolds for tissue engineering applications. ${ }^{[6,14]}$

The XRD was used to study the type of minerals formed on the surface of the peptide amphiphile nanofibers after gels were incubated for $24 \mathrm{~h}$. The mineralized peptide nanofibers showed the characteristic patterns of the hydroxyapatite ${ }^{[15]}$ (Figures $3 \mathrm{a}$ and S3a), as the diffraction peaks at (211), (300) and (004) match with the peaks revealed by the hydroxyapatite. Non-mineralized peptide nanofibers were also characterized by XRD and showed no characteristic hydroxyapatite peaks (Figures $3 \mathrm{a}, \mathrm{S} 3 \mathrm{~b}$ and S3c). The peaks associated with $\mathrm{NaCl}$ were also observed even after five times of washing prior to the preparation of XRD samples (Figures 3a and S3d).

TGA was used to study the organic/inorganic ratio of mineralized peptide nanofibers under elevated temperatures (Figure $3 \mathrm{~b}$ ). TGA of the $\mathrm{E}_{3}-\mathrm{PA} /$ Hydroxyapatite composite material demonstrated a mass loss of $7 \%$ up to around $200^{\circ} \mathrm{C}$, which corresponds to adsorbed water. In addition, there was a characteristic mass loss between $200^{\circ} \mathrm{C}$ and $260^{\circ} \mathrm{C}$, which is attributed to the morphology change of the DCPD (dicalcium phosphate dihydrate) impurity phase to DCPA (dicalcium phosphate anhydrous). The weight loss between $300^{\circ} \mathrm{C}$ and $600^{\circ} \mathrm{C}$ can be attributed to the decomposition of peptide nanofibers. Decomposition of hydroxyapatite minerals was not observed because higher temperature is required for decomposition of hydroxyapatite (Figure S4a). ${ }^{[15 a-c]}$ Non-mineralized peptide amphiphile nanofibers were also characterized by TGA, where an initial mass loss of $7 \%-8 \%$ was observed between a

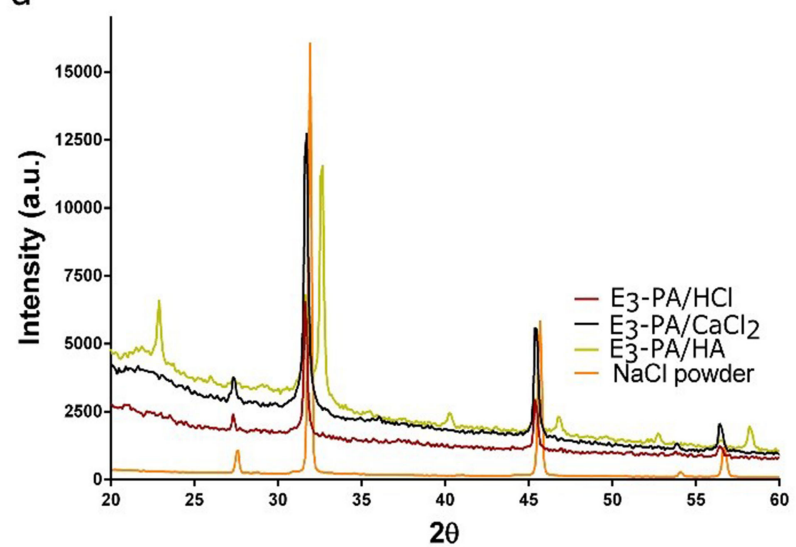

b

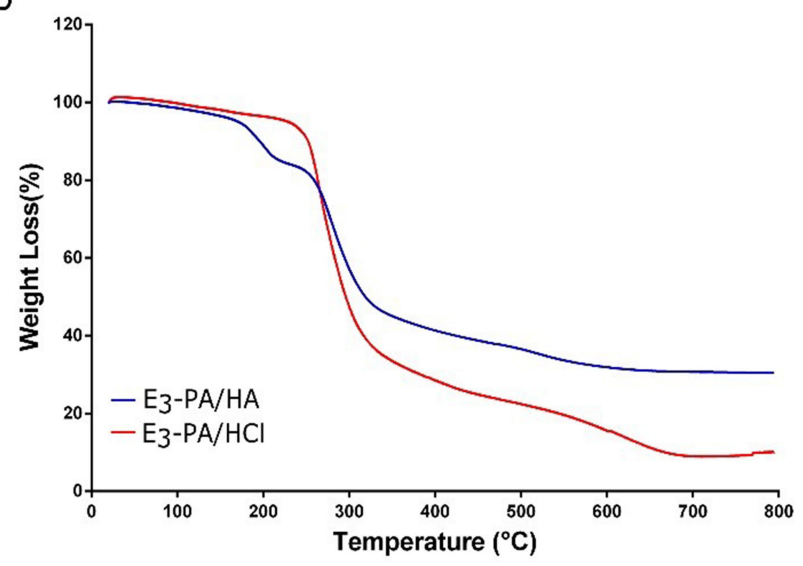

Figure 3. (a) XRD patterns of mineralized and non-mineralized peptide nanofibers and $\mathrm{NaCl}$ powder, and (b) TGA analysis of mineralized and nonmineralized peptide nanofibers. $\mathrm{E}_{3}-\mathrm{PA} / \mathrm{HCl}$ peptide nanofibers were prepared by mixing $\mathrm{E}_{3}-\mathrm{PA}$ with $\mathrm{HCl} ; \mathrm{E}_{3}-\mathrm{PA} / \mathrm{CaCl}_{2}$ mineralized peptide nanofibers were prepared by mixing $\mathrm{E}_{3}-\mathrm{PA}$ with only $\mathrm{CaCl}_{2} ; \mathrm{E}_{3}-\mathrm{PA} / \mathrm{HA}$ mineralized peptide nanofibers were prepared by mixing $\mathrm{E}_{3}-\mathrm{PA}$ with $\mathrm{CaCl}_{2}$ followed by addition of $\left(\mathrm{NH}_{4}\right)_{2} \mathrm{HPO}_{4}$.

$20^{\circ} \mathrm{C}$ to $250^{\circ} \mathrm{C}$, which corresponds to adsorbed water inside the structure. Above $250^{\circ} \mathrm{C}$, non-mineralized nanofibers showed no characteristic hydroxyapatite peaks (Figure S4b).

Rheological characterization of mineralized and non-mineralized peptide nanofibers was performed to understand their viscoelastic properties. The mechanical stiffness of peptide nanofibers was increased by the mineralization of nanofibers (Figure 4a). Bone is an excellent example of a composite material that combines organic and inorganic components. ${ }^{[4 b]}$ This association helps natural materials to combine strength with toughness, which makes them damage-tolerant. Rheology results indicated that, while non-mineralized peptide nanofibers demonstrated $\mathrm{G}^{\prime}$ values ranging from $0.5 \mathrm{kPa}$ to $2 \mathrm{kPa}, \mathrm{G}^{\prime}$ values of mineralized peptide nanofibers were in the range of $9 \mathrm{kPa}$ to $13 \mathrm{kPa}$ (Figure S5). This increase in storage moduli could result from the formation of biominerals that serve as energydissipating points within the PA gel, such that any applied force to the structure is absorbed by the minerals while the overall network remains intact. In addition, energy dissipating points 
a

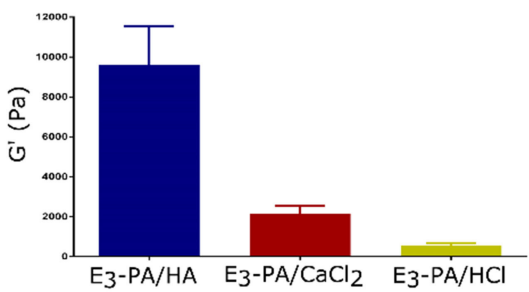

b

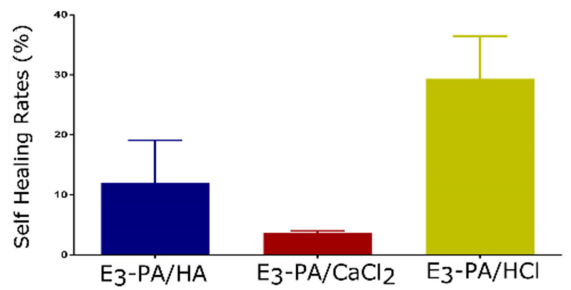

C

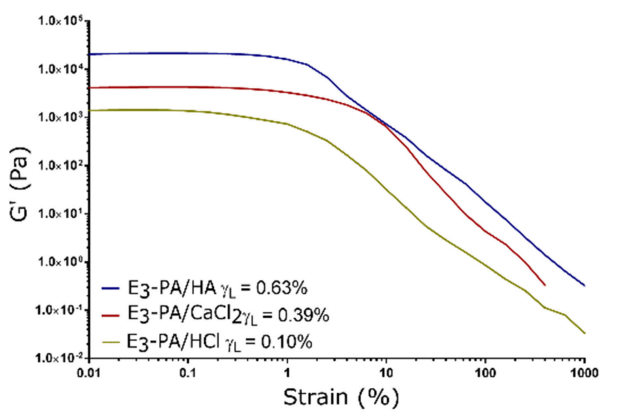

Figure 4. (a) Equilibrium storage modulus, (b) self-healing properties and (c) limiting strain values of mineralized and non-mineralized peptide nanofibers.

form plastic zones that cover cracks and reduce the driving force required for the crack paths. ${ }^{[16]}$

The self-healing ability of the mineralized and non-mineralized peptide nanofibers was determined by performing a thixotropic test (Figure S5). A high shear load was applied to break both covalent and noncovalent bonds in the PA gel, including any mineral structures. The recovery rates of mineralized and non-mineralized gels were then calculated (Figure 4b). When peptide nanofiber formation was triggered by $\mathrm{H}^{+}$ions, the recovery rate of the gel was calculated to be almost $40 \%$; however, when gelation was triggered with $\mathrm{Ca}^{2+}$ ions, recovery rate decreased from $40 \%$ to $4 \%$. As such, when gelation was triggered by $\mathrm{CaCl}_{2}$ rather than $\mathrm{HCl}$, calcium-mediated ionic bridges formed intra- and interfiber crosslinks that were stronger than hydrogen bonds but were also more difficult to re-establish following breakage. ${ }^{[11,, d]}$

Mineralized peptide nanofibers were also characterized in terms of their self-healing properties. Calcium phosphatebearing composite gel systems demonstrated lower recovery rates compared to $\mathrm{E}_{3}-\mathrm{PA} / \mathrm{HCl}$ gels. However, the recovery rate of composite gels was higher compared to the $\mathrm{E}_{3}-\mathrm{PA} / \mathrm{CaCl}_{2}$ gel system because of the presence of soluble ions inside the composite structure and the organic content within composite gels. While high shear loads are expected to deform biomineral structure and break both noncovalent and covalent bonds, soluble ions inside the gel might have recreated supersaturation points and initiated the nucleation of minerals onto nanofibers during the recovery phase, leading to an enhanced capacity for self-healing. Similarly, organic elements (i. e. peptide amphiphile nanofibers) within the mineralized gel may have acted as a viscoelastic glue and prevented the deformation of the composite structure under high shear loads.

The rheological measurements were used to determine the limiting strain amplitude of mineralized and non-mineralized peptide amphiphile nanofibers. In linear viscoelastic range, under elastic deformation, materials can preserve their elastic properties by keeping the storage modulus constant. ${ }^{[12]} \mathrm{How}$ ever, once a strain threshold, called limiting strain amplitude, is crossed, plastic deformation occurs and the modulus of the material starts decreasing under increasing strain values. ${ }^{[12]}$ The elasticity of materials can thus be determined by measuring the length of the linear viscoelastic range, which can also be considered as a measure of stability of the material. The linear viscoelastic range of mineralized peptide nanofibers was slightly higher compared to non-mineralized peptide nanofibers. Therefore, the stability of these composite materials was higher compared to their non-mineralized counterparts (Figure 4c).

\section{Cell Viability and Behavior on Mineralized PA Nanofibers}

The effect of mineralized peptide nanofiber systems on cellular behavior was investigated by evaluating the viability, adhesion and proliferation of Saos-2 cells seeded on peptide-coated surfaces or uncoated TCP (Figure 5). Saos-2 is a human osteosarcoma cell line and serves as a common model for osteoblast-like cells in bone regeneration and osteogenic differentiation studies. ${ }^{[17]}$ Adhesion of Saos- 2 cells on the mineralized peptide nanofiber network system was studied after $4 \mathrm{~h}$ of incubation, and the number of adherent cells on peptide nanofibers was found to be greater than glass surfaces (Figure 5a). The effect of mineralized peptide nanofibers on the viability of Saos-2 cells was also tested by Calcein AM staining after $24 \mathrm{~h}$ of incubation. Cells were viable on all surfaces over this period (Figures $5 b, d, f, h$ ). Cellular viability on the peptide nanofibers was comparable with uncoated surfaces (TCP), which indicates the biocompatibility of mineralized peptide nanofibers (Figure $5 b$ ). The interaction of cells with the peptide nanofibers was further evaluated by actin cytoskeleton staining (phalloidin/TO-PRO-3 staining) and examination of cell spreading. Cells adhered firmly on the peptide nanofiber networks and formed cytoskeletal attachments (Figures $5 \mathrm{e}, \mathrm{g}$ ). When proliferation profiles of cells were studied on different surfaces, the proliferation of cells on mineralized peptide nanofibers were found to be comparable to TCP on day 1, but decreased compared to non-mineralized peptide nanofibers and TCP on day 3 (Figure $5 \mathrm{c}$ ), which could be an indicator of cellular differentiation since decreased cell proliferation is associated with increases in osteoblast differentiation markers. ${ }^{[18]}$ 


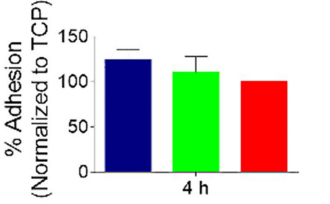

b

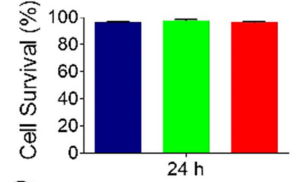

c

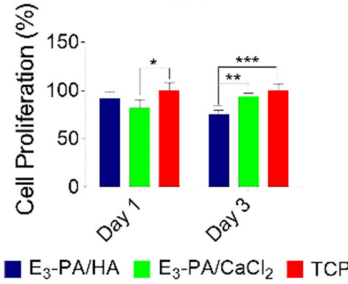

Figure 5. Adhesion, spreading, viability, and cell proliferation of Saos-2 cells cultured on mineralized peptide nanofibers. (a) Relative adhesion of Saos-2 cells on the peptide nanofibers after $4 \mathrm{~h}$. (b) Relative cell viability on day 1 and live-dead images showing that nanofiber networks are biocompatible $(\mathrm{d}, \mathrm{f}, \mathrm{h})$. Scale bars are $100 \mu \mathrm{m}$. (c) Relative cell proliferation on days 1 and 3 . $(e, g$, i) Spreading of Saos-2 cells, as characterized by actin fiber staining (nuclei stained with TO-PRO3 (blue), actin fibers stained with TRITCconjugated phalloidin (green). Scale bars are $20 \mu \mathrm{m}$.

\section{Molecular Analysis of Osteogenic Differentiation}

ALP is an important early marker of osteogenic differentiation and functions in releasing inorganic phosphate units from pyrophosphate, which is an integral step of the biomineralization process. ${ }^{[19]}$ We tested the ALP activity of Saos- 2 cells cultured on mineralized peptide nanofibers, non-mineralized peptide nanofibers and TCP surfaces after 3, 7 and 14 days of incubation in osteogenic medium. Cells cultured on these mineralized matrices showed significantly enhanced ALP activity compared to non-mineralized peptide nanofiber and TCP groups on days 7 and 14 (Figure 6a).

Quantitative real-time RT-PCR measurements were performed to further evaluate the osteogenic differentiation process on mineralized peptide nanofibers, which were found to stimulate the expression of several osteogenic genes such as collagen I, osteocalcin and the transcription factor Runx2 in Saos- 2 cells. Runx2 is a Runt-related transcription factor that is essential for osteoblast differentiation and regulates the expression of several osteoblastic genes such as $\alpha(\mathrm{l})$ collagen, osteopontin, bone sialoprotein, and the skeletal-specific osteocalcin. ${ }^{[20]}$ A characteristic collagen I-rich matrix is also deposited at the early stages of osteogenic differentiation, acting as a template for mineralization. ${ }^{[21]}$ Similarly, osteocalcin is a noncollagenous protein that is crucial for the mineralization of bone, and is usually used as a late marker of osteogenic differentiation. ${ }^{[21]}$

Runx2 expression of cells on mineralized peptide nanofibers was significantly upregulated by $\sim 2.0$ and $\sim 18.1$ folds compared to cells on non-mineralized peptide nanofibers and TCP, respectively, on day 7 (Figure $6 \mathrm{~b}$ ). Collagen I expression of cells on mineralized peptide nanofibers was also enhanced by $\sim 1.2$
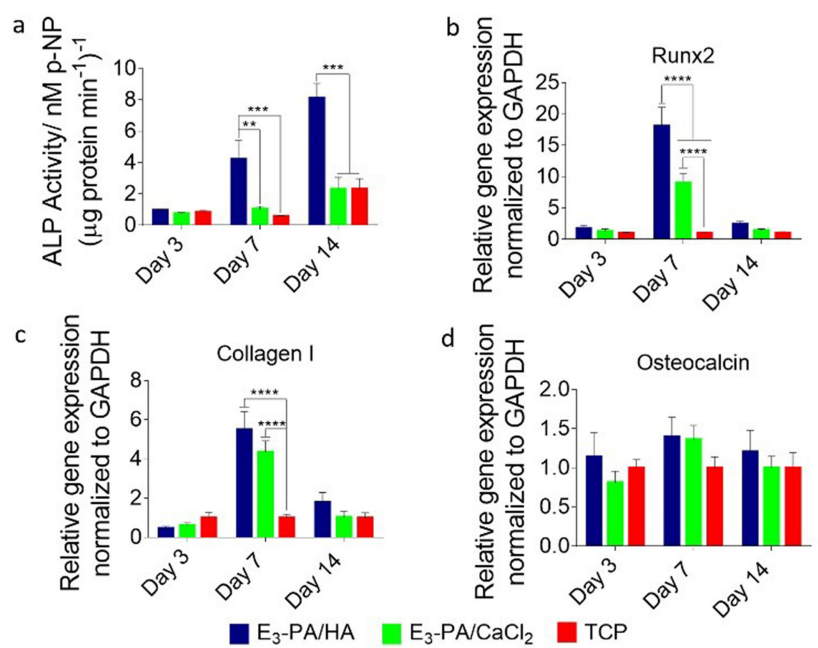

Figure 6. Molecular analysis of osteogenic differentiation. (a) ALP activity of Saos- 2 cells on days 3, 7 and 14 of osteogenic differentiation. (b-d) Gene expression analysis of Runx2 (b), Collagen I (c), and osteocalcin (d) on days 3, 7 and 14 of osteogenic differentiation. The expression level of each gene was normalized against TCP; GAPDH was used as internal control. Values represent mean \pm SEM $\left({ }^{* * *} \mathrm{p}<0.0001,{ }^{* * *} \mathrm{p}<0.001,{ }^{* *} \mathrm{p}<0.01\right)$.

and $\sim 5.5$ folds compared to cells on non-mineralized peptide nanofibers and TCP, respectively (Figure $6 c$ ). On day 14, expression of osteocalcin was higher on both mineralized peptide nanofibers and non-mineralized peptide nanofibers compared to TCP (Figure 6d). In addition, cells on mineralized peptide nanofibers showed collagen I immunostaining on day 7 (Figure S6).

In summary, mineralized peptide nanofibers were found to support osteoblast-like cell attachment and viability. Cells on mineralized peptide nanofibers showed enhanced osteogenic differentiation compared to cells on non-mineralized peptide nanofibers and TCP. These results indicate that mineralized peptide hydrogels are promising osteoinductive substrates. ${ }^{[14 a}$, 22] In addition, presence of calcium phosphate minerals on peptide nanofiber system makes them mechanically superior, which might lead to enhanced osteogenic differentiation of cells. ${ }^{[23]}$

\section{Conclusions}

In this work, we demonstrated the synthesis of mineralized peptide amphiphile nanofiber networks for induction of osteogenic differentiation. An anionic nanofiber gel matrix was used as a template for the formation of hydroxyapatite nanocrystals, and its nucleation, growth and morphological properties were investigated by TEM, SEM, and AFM. XRD results demonstrated that the peptide nanofiber template promotes the formation of hydroxyapatite crystals, while the mineral and organic components of the peptide nanofiber/hydroxyapatite composite were determined by TGA analysis. Rheological and thixotropic measurements showed that mineralized peptide nanofibers were mechanically stronger compared to nonmineralized counterparts, and the recovery rate of mineralized 
peptide nanofibers was considerably higher. Based on the ALP activity assay and osteogenic gene expression analysis, the presence of hydroxyapatite in peptide nanofibers favored osteogenic differentiation. The stimulating effect on osteogenesis by hydroxyapatite surfaces may result from the altered cell-extracellular matrix interactions; as such, the dynamic behavior of focal adhesions should be investigated in further studies. Our findings suggest that scaffold mineralization is a promising means of enhancing osteogenic differentiation on peptide nanofiber systems.

\section{Experimental Section}

\section{Materials}

All protected amino acids, lauric acid, Fmoc-Glu(OtBu)-Wang resin (100-200 mesh), $\quad N, N, N^{\prime}, N^{\prime}$-tetramethyl-O-(1H-benzotriazole-1-yl) uronium hexafluorophosphate (HBTU) and diisopropylethylamine (DIEA) were purchased from Novabiochem ABCR or Sigma-Aldrich. Calcein-AM and other cell culture materials were obtained from Invitrogen or Thermo-Fisher. All other chemicals and materials used in this study were purchased from Thermo-Fisher, Merck, Alfa Aesar or Sigma-Aldrich.

\section{Synthesis and Characterization of PA Molecules}

Lauryl-Val-Val-Ala-Gly-Glu-Glu-Glu ( $\left.\mathrm{E}_{3}-\mathrm{PA}\right)$ was synthesized by Fmoc solid phase peptide synthesis method. Fmoc-Glu(OtBu)-Wang resin (100-200 mesh) (Novabiochem) served as the solid support. Amino acid couplings were carried out with 2 molar equivalents of Fmocprotected amino acid, 1.95 molar equivalents of HBTU, and 3 molar equivalents of DIEA for $2 \mathrm{~h}$. Fmoc groups were removed after each coupling step with $20 \%$ piperidine/dimethylformamide (DMF) for $20 \mathrm{~min}$. 10\% acetic anhydride-DMF solution was used to block the unreacted amine groups after each coupling step. Removal of protecting groups and peptide molecules from the solid support was carried out by trifluoroacetic acid (TFA) cleavage cocktail $(95 \%$ TFA, $2.5 \%$ water, $2.5 \%$ triisopropyl silane) for $3 \mathrm{~h}$. Excess TFA was removed by rotary evaporation. Synthesized $E_{3}-P A$ was then precipitated in diethyl ether overnight. The precipitate was collected by centrifugation and dissolved in ultra-pure water. This solution was frozen at $-80^{\circ} \mathrm{C}$ followed by lyophilization. The purity of the peptide molecule was assessed by using an Agilent 6530 quadrupole time of flight (Q-TOF) mass spectrometer equipped with an electrospray ionization (ESI) source and a reverse-phase analytical high performance liquid chromatography (HPLC) system. The $E_{3}-P A$ molecule was purified with a preparative HPLC system (Agilent 1200 series). The $E_{3}-\mathrm{PA}$ was then freeze-dried and reconstituted in ultrapure water at $\mathrm{pH} 7.4$ before use.

\section{Preparation of Mineralized Gels}

Stock solutions of $\left(\mathrm{NH}_{4}\right)_{2} \mathrm{HPO}_{4}$ and $\mathrm{CaCl}_{2}$ were prepared in ultrapure water. The $\mathrm{E}_{3}-\mathrm{PA}$ was also dissolved in ultra-pure water at neutral $\mathrm{pH}$ at $1 \%(\mathrm{w} / \mathrm{v})$ concentration. Self-assembled nanofibers were prepared by pipetting the negatively-charged $\mathrm{E}_{3}-\mathrm{PA}$ solution on a silicon wafer and adding positively-charged $\mathrm{CaCl}_{2}$ to trigger charge neutralization-based gel formation behavior. A control gel was also prepared using addition of $\mathrm{HCl}$ solution instead of $\mathrm{CaCl}_{2}$ to determine the importance of a calcium template for mineral formation. The mixture was incubated for $30 \mathrm{~min}$ to obtain a stable gel, and a mineralized peptide nanofiber system was obtained by adding $\left(\mathrm{NH}_{4}\right)_{2} \mathrm{HPO}_{4}$ dropwise following the incubation period. Mineral deposition in the absence of gel formation was also studied by repeating the aforementioned protocol with ultrapure water instead of the $E_{3}-P A$ solution.

\section{SEM Imaging of Samples}

Morphology of mineralized and non-mineralized peptide nanofiber gels were studied by SEM. Before SEM examination, $60 \mu \mathrm{L}$ samples were prepared by combining $20 \mu \mathrm{L}$ of $(1 \% \mathrm{w} / \mathrm{v}) \mathrm{E}_{3}$-PA solution with $20 \mu \mathrm{L}$ of $(100 \mathrm{mM}) \mathrm{CaCl}_{2}$ solution and $20 \mu \mathrm{L}$ of $(100 \mathrm{mM})$ calcium phosphate mineral $\left(\left(\mathrm{NH}_{4}\right)_{2} \mathrm{HPO}_{4}\right)$ solution. Mineralized PA hydrogels were dehydrated in $20 \%, 40 \%, 60 \%$ and $80 \%$ ethanol solutions for $10 \mathrm{~min}$ in each solution, and finally incubated in absolute ethanol for $3-4 \mathrm{~h}$. Then, the gel was critical point dried with an Autosamdri ${ }^{\circledR}-815 B$ Tousimis Critical Point Dryer and coated with $6 \mathrm{~nm} \mathrm{Au} / \mathrm{Pd}$ by sputtering before SEM imaging. Finally, A FEI Quanta 200 FEG scanning electron microscope with an ETD detector was used to visualize the resulting networks. In order to determine the effect of $\mathrm{E}_{3}-\mathrm{PA}$ on the mineralization process, control experiments were performed in the absence of PA molecules.

\section{TEM Imaging of Samples}

Peptide nanofibers were prepared and mineralized on carboncoated TEM grids to preserve their nanoscale organization, which is critical for avoiding imaging artifacts. A drop of PA solution $(0.05 \%$ w/v) was mounted on a holey grid, $5 \mathrm{mM}$ of $\mathrm{CaCl}_{2}$ and $5 \mathrm{mM}$ of $\left(\mathrm{NH}_{4}\right)_{2} \mathrm{HPO}_{4}$ solutions were dropped on the grid at a 1:10 ratio, and the mixture was incubated for several minutes to obtain calcium phosphate minerals. In combination with TEM imaging, the samples were also analyzed by EDX to confirm the presence of calcium and phosphorus following the mineralization process. In order to determine the effect of peptide amphiphiles, control experiments were conducted in absence of $\mathrm{E}_{3}-\mathrm{PA}$. To prepare control samples; ultra-pure water was dropped onto carbon-coated TEM grid instead of $\mathrm{E}_{3}-\mathrm{PA}$, and $\mathrm{CaCl}_{2}$ and $\left(\mathrm{NH}_{4}\right)_{2} \mathrm{HPO}_{4}$ solutions were then added to promote the formation of calcium phosphate.

\section{AFM Analysis of Samples}

Mineralized peptide nanofibers were also imaged by AFM in tapping mode after deposition onto a silicon wafer. $E_{3}$-PA $(0.05 \%$ $\mathrm{w} / \mathrm{v})$ solution was first drop cast onto a silicon wafer, and $5 \mathrm{mM}$ of $\mathrm{CaCl}_{2}$ solution was then added to induce the nanofiber formation of $\mathrm{E}_{3}$-PA. Finally, $5 \mathrm{mM}\left(\mathrm{NH}_{4}\right)_{2} \mathrm{HPO}_{4}$ solution was added in order to facilitate the deposition of calcium phosphate on peptide nanofibers. Samples were dried at room temperature and imaged using a commercial atomic force microscope (MFP3D, Asylum Research).

\section{XRD Analysis of Biomineralization}

In order to determine the presence and type of minerals on the peptide scaffolds, XRD spectra of mineralized and non-mineralized PAs were obtained with a Panalytical X'pert Pro Multi-Purpose XRay Diffractometer. A total volume of $560 \mu \mathrm{L}$ of gel was prepared by mixing $\mathrm{E}_{3}-\mathrm{PA}, \mathrm{CaCl}_{2}$ and $\left(\mathrm{NH}_{4}\right)_{2} \mathrm{HPO}_{4}$ at a molar ratio of 1:10:10, respectively. The samples were immersed into liquid nitrogen, lyophilized, and powdered prior to XRD measurements. Two control samples, $\mathrm{E}_{3}-\mathrm{PA} / \mathrm{HCl}$, prepared by substituting $\mathrm{HCl}$ instead of $\mathrm{CaCl}_{2}$ during gel preparation, and $\mathrm{E}_{3}-\mathrm{PA} / \mathrm{CaCl}_{2}$, prepared without $\left(\mathrm{NH}_{4}\right)_{2} \mathrm{HPO}_{4}$ to prevent the formation of calcium phosphate, were also measured in order to determine the differences between mineralized and non-mineralized peptide nanofibers. 


\section{Oscillatory Rheology}

An Anton Paar Physica RM301 Rheometer device was used in order to characterize the viscoelastic properties of peptide hydrogels and evaluate the changes in mechanical properties that occur following the mineralization of PA molecules. The self-assembly and mineralization of the PAs were induced on the plate of the rheometer. Three gel formulations were prepared to evaluate the rheological differences between mineralized and non-mineralized PA molecules. In mineralized peptide nanofiber gel experiments, $250 \mu \mathrm{L}$ of $(1 \% \mathrm{~W} / \mathrm{v}) \mathrm{E}_{3}$-PA was placed on the plate of the rheometer, $25 \mu \mathrm{L}$ of $100 \mathrm{mM} \mathrm{CaCl} 2$ solution was added dropwise to facilitate the formation of self-assembled peptide nanofibers, and $25 \mu \mathrm{L}$ of $100 \mathrm{mM}\left(\mathrm{NH}_{4}\right)_{2} \mathrm{HPO}_{4}$ solution was then added to obtain calcium phosphate minerals. In addition, to determine the mechanical effects of mineral formation, two control experiments were carried out using $\mathrm{CaCl}_{2}$ (in the absence of $\left.\left(\mathrm{NH}_{4}\right)_{2} \mathrm{HPO}_{4}\right)$ or $\mathrm{HCl}$ as inducing agents for nanofiber formation. All measurements were carried out at room temperature. Gelation kinetics of the mineralized and nonmineralized peptide nanofiber gels were characterized by timedependent rheology. During the time-sweep test, strain and angular frequency were held constant at $0.01 \%$ and $10 \mathrm{rads}^{-1}$, respectively. To determine the linear viscoelastic range of the gels, an amplitude sweep test was conducted at a constant angular frequency of $10 \mathrm{rads}^{-1}$ by logarithmically ramping the strain amplitude from 0.01 to $1000 \%$.

The self-healing (thixotropic) properties of mineralized peptide nanofiber gels were also examined. Self-assembly and mineralization of the PA nanofibers were conducted on the plate of the rheometer to eliminate sample transfer-related disturbances in the long-range organization of the materials. Three gel formulations were prepared to identify the differences in self-healing properties between mineralized and non-mineralized peptide nanofiber gels. In mineralized peptide nanofiber gel experiments, $250 \mu \mathrm{L}$ of $(1 \% \mathrm{w} /$ v) $E_{3}-\mathrm{PA}$ was placed on the plate of the rheometer, $25 \mu \mathrm{L}$ of $100 \mathrm{mM} \mathrm{CaCl}$ solution was added dropwise to facilitate the formation of self-assembled peptide nanofibers, and $25 \mu \mathrm{L}$ of $100 \mathrm{mM}\left(\mathrm{NH}_{4}\right)_{2} \mathrm{HPO}_{4}$ solution was then added to obtain calcium phosphate minerals. In addition, two control experiments were carried out using $\mathrm{CaCl}_{2}$ (in the absence of $\left.\left(\mathrm{NH}_{4}\right)_{2} \mathrm{HPO}_{4}\right)$ or $\mathrm{HCl}$ solutions as inducing agents for nanofiber formation. During thixotropic measurements, peptide nanofibers were first incubated on the rheometer plate for $15 \mathrm{~min}$ to ensure the stability of the gel structure. The peptide nanofiber gels were studied in the linear viscoelastic region under $0.01 \%$ strain for $5 \mathrm{~min}$ (loading phase), the strain was increased to $1000 \%$ logarithmically for $1 \mathrm{~min}$ to break the chemical bonds and deform the mineralized peptide nanofibers (decomposition phase) and the gel was allowed to recover by decreasing the strain back to $0.01 \%$ over $10 \mathrm{~min}$ (recovery phase). All measurements were carried out at room temperature.

\section{Thermogravimetric Analysis}

A TA Instruments TGA Q500 device was employed in order to determine the organic/inorganic content of the mineralized and non-mineralized peptide nanofibers. Mineralized and non-mineralized peptide nanofibers were prepared using the procedure described for the preparation of XRD samples. The temperature range used in the experiments was between 0 and $800^{\circ} \mathrm{C}$, and heating rate was $15^{\circ} \mathrm{C} / \mathrm{min}$ in a $\mathrm{N}_{2}$ environment.

\section{Cell Culture and Maintenance}

Saos-2 cells (human osteosarcoma cell line, ATCCR HTB-85TM) were used in all cell culture experiments at passage numbers between 20 to 25 . Cells were cultured in $75 \mathrm{~cm}^{2}$ flasks at $37^{\circ} \mathrm{C}$ in a humidified incubator and supplied with $5 \% \mathrm{CO}_{2}$. Saos-2 cells were maintained in low glucose Dulbecco's Modified Eagle's Medium (DMEM) with L-glutamine, supplemented with $10 \%$ fetal bovine serum (FBS) and $1 \%$ penicillin/streptomycin. All cell experiments were carried out after the cells had reached $90 \%$ confluency. The culture medium was changed every 3-4 days. The cell medium was replaced with osteogenic medium (DMEM with 10\% FBS supplemented with $10 \mathrm{mM} \beta$-glycerophosphate, $50 \mu \mathrm{g} \mathrm{mL}^{-1}$ ascorbic acid and $10 \mathrm{nM}$ dexamethasone) after the seeded cells had reached confluency.

\section{Viability Assay}

The viability of Saos- 2 cells incubated on mineralized PA nanofibers, non-mineralized PA nanofibers and bare tissue culture plates (TCP) was studied by Live/Dead Assay (Invitrogen). Briefly, cells were seeded on mineralized PA nanofibers, non-mineralized PA nanofibers and bare 96-well tissue culture plates at a density of $5 \times 10^{3}$ cells/well. After $24 \mathrm{~h}$ of incubation, cell medium was discarded, and cells were washed with phosphate buffered saline (PBS) and incubated with $2 \mu \mathrm{M}$ Calcein-AM and $2 \mu \mathrm{M}$ EthD-1 in PBS for $30 \mathrm{~min}$ at room temperature. After incubation, images were taken at three random points per well by fluorescence microscopy (Zeiss, Axio Scope A1) at $100 \times$ magnification. All samples were analyzed as three wells per group. Live and dead cells were counted by using ImageJ.

\section{Cytoskeletal Staining of Saos-2 Cells on Mineralized PA Nanofibers}

Cells were seeded on top of mineralized PA nanofiber-coated, nonmineralized PA nanofiber-coated and uncoated (bare TCP) surfaces at a density of $4 \times 10^{4}$ cells per $13 \mathrm{~mm}$ coverslip. After 3 days of culture, phalloidin/TO-PRO-3 staining was performed to evaluate the differences in cytoskeletal organization. Before staining, cells were fixed with $4 \%$ formaldehyde for $15 \mathrm{~min}$ and permeabilized with $0.1 \%$ Triton- $X$ for $10 \mathrm{~min}$ at room temperature. Samples were incubated with $3 \%(\mathrm{w} / \mathrm{v})$ bovine serum albumin (BSA)/PBS for blocking for $30 \mathrm{~min}$. Actin filaments of the cells were initially stained with 1:500 diluted FITC-conjugated phalloidin (Thermo Fisher) in $3 \%(\mathrm{w} / \mathrm{v}) \mathrm{BSA} / \mathrm{PBS}$ for $20 \mathrm{~min}$. After serial washing steps, samples were stained with 1:1000 diluted TO-PRO-3 (Thermo Fisher) or 1:3000 diluted DAPI (Thermo Fisher) for 20 min for the visualization of nuclei. Coverslips were mounted with Prolong Gold Antifade Reagent (Invitrogen). Cytoskeletal organizations of cells were observed using a Zeiss LSM 510 confocal microscope at $630 \times$ magnification.

\section{Cell Adhesion Assay}

Cell adhesion experiments were performed under serum-free conditions. Cells were incubated for $1 \mathrm{~h}$ in serum-free DMEM medium supplemented with $4 \mathrm{mg} / \mathrm{mL}$ BSA and $50 \mu \mathrm{g} / \mathrm{mL}$ cycloheximide at standard culture conditions before seeding. After $1 \mathrm{~h}$, cells were removed from tissue culture plate by trypsinization and seeded onto the coated 96-well plates. After $4 \mathrm{~h}$ of incubation in serum-free medium under standard culture conditions, Calcein AM (Invitrogen) staining $(2 \mu \mathrm{M})$ was performed for 40 min according to the manufacturer's instructions. Cell adhesion was quantified directly by counting the number of cells using ImageJ program 
from fluorescence microscopy images, and results were then normalized to bare TCP. Images were taken from 5 different random locations per well, and the experiment was carried out with $\mathrm{n}=5$.

\section{Cell Proliferation Assay}

Proliferation of cells on coatings was assessed using BrdU assay (Roche). Cells were cultured on PA-coated wells and uncoated TCP at a density of $3 \times 10^{3}$ cells/well. Cells were incubated in standard cell culture medium supplemented with $100 \mu \mathrm{M}$ BrdU labeling solution for $24 \mathrm{~h}$ and $72 \mathrm{~h}$. At the end of the incubation period, BrdU incorporation assay was performed according to the manufacturer's instructions. Briefly, cells were fixed with FixDenat for $30 \mathrm{~min}$ and anti BrdU-POD solution was added into wells. Following $90 \mathrm{~min}$ of incubation and subsequent tapping, substrate solution was added into wells and proliferation rates of the cells were quantified by measuring their absorbance $(370 \mathrm{~nm}$, with $492 \mathrm{~nm}$ reference wavelength) with a microplate reader.

\section{ALP Activity Assay}

In order to measure the ALP activity of Saos-2 cells, degradation of p-nitrophenol through endogenous ALP activity was quantified after 3, 7 and 14 days of culture in osteogenic medium. Briefly, cells were seeded on mineralized PA nanofiber-coated, non-mineralized PA nanofiber-coated and uncoated (bare TCP) surfaces of 48-well plates at a density of $2 \times 10^{4}$ cells per well. Cells were rinsed with PBS at predetermined time points. M-PER protein extraction kit (Thermo) with $5 \%$ protease inhibitor solution was used to extract proteins. Pierce BCA protein assay (Thermo) was performed to quantify the amount of proteins obtained from the cells according to the manufacturer's protocol. To measure ALP activity, $50 \mu \mathrm{L}$ of the protein sample was incubated with $150 \mu \mathrm{L}$ of $p$-nitrophenol phosphate substrate in 96 -well plates for $30 \mathrm{~min}$ on a shaker. Serial dilutions of $p$-nitrophenol in $0.25 \mathrm{M} \mathrm{NaOH}$ solution were used as standards. Finally, the optical density of the samples was determined at $405 \mathrm{~nm}$ using a Spectramax M5 microplate reader and ALP results were normalized to the amount of total proteins at each time point tested.

\section{Immunocytochemistry}

Before immunocytochemistry stainings, differentiated cells were fixed with $4 \%$ formaldehyde for $15 \mathrm{~min}$ and permeabilized with $0.5 \%$ Triton- $X$ for $10 \mathrm{~min}$ at room temperature. $3 \mathrm{wt} \%$ BSA/PBS was used for blocking for $1 \mathrm{~h}$, while a mouse-anti-human, collagen I monoclonal antibody (Abcam-ab6308) and a goat-anti-mouse, IgG H\&L DyLight 488 conjugated secondary antibody (MilliporeAP124JA4) were used for immunostaining. Actin filaments were stained with TRITC-conjugated phalloidin and cell nuclei were stained with TO-PRO-3 iodide. Samples were visualized with a Zeiss LSM 510 confocal microscope.

\section{Gene Expression Analysis}

For gene expression studies, Saos-2 cells were seeded on mineralized PA nanofiber-coated, non-mineralized PA nanofibercoated and uncoated (bare TCP) surfaces of 6-well plates at a density of $2.5 \times 10^{5}$ cells per $\mathrm{cm}^{2}$. After cells had reached confluency, their media were replaced with osteogenic medium, and gene expression profiles of Runx2, collagen I, and osteocalcin were evaluated by quantitative RT-PCR (qRT-PCR) analysis to investigate the osteogenic differentiation process. RNA isolation from Saos-2 cells seeded on mineralized PA nanofiber-coated, non-mineralized PA nanofiber-coated and uncoated surfaces was performed by using TRIzol (Invitrogen) according to the manufacturer's instructions after 3, 7 and 14 days of incubation in osteogenic medium. Yield and purity of extracted RNAs were assessed by Nanodrop 2000 (Thermo Scientific). Samples were diluted to a concentration of $100 \mathrm{ng} / \mu \mathrm{L}$ prior to their use. Primers for PCR amplification of Runx2, Collagen I, osteocalcin and GAPDH are shown in Table S1. CDNA synthesis from RNA and qRT-PCR were performed using SuperScript III Platinum SYBR Green One-Step qRT-PCR Kit according to the manufacturer's instructions. mRNA levels were calculated and normalized to GAPDH according to comparative $\mathrm{Ct}$ method for each target gene. ${ }^{[24]}$

\section{Acknowledgements}

G.T. was supported by TUBITAK-BIDEB 2211-C PhD fellowship. This work is partially supported by TUBITAK and TUBA. We acknowledge Dr. A. D. Ozkan for helpful discussions and thank Mr. M. Guler for help in TEM imaging.

\section{Conflict of Interest}

The authors declare no conflict of interest.

Keywords: Biomineralization · osteogenic differentiation peptides nanofibers

[1] H. Yao, M. Dao, T. Imholt, J. Huang, K. Wheeler, A. Bonilla, S. Suresh, C. Ortiz, Proc. Natl. Acad. Sci. USA 2010, 107, 987-992.

[2] a) F. Nudelman, N. A. Sommerdijk, Angew. Chem. Int. Ed. 2012, 51, 65826596; b) K. Naka, H. Cölfen, Biomineralization II: Mineralization Using Synthetic Polymers and Templates, Vol. 2, Springer Science \& Business Media, 2007, pp 1-77.

[3] a) L. Addadi, S. Weiner, Proc. Natl. Acad. Sci. USA 1985, 82, 4110-4114; b) E. Beniash, Wiley Interdiscip. Rev. Nanomed. Nanobiotechnol. 2011, 3, 47-69.

[4] a) E. A. Zimmermann, H. D. Barth, R. O. Ritchie, JOM 2012, 64, 486-493; b) R. O. Ritchie, Nat. Mater. 2011, 10, 817-822.

[5] C. Carney, M. Fricke, S. Harry, H. Imai, R. Kniep, K. Sato, S. Sewell, P. Simon, D. Volkmer, D. Wright, Biomineralization I: Crystallization and Self-Organization Process, Vol. 270, Springer, 2006, pp 127-153.

[6] a) T. D. Sargeant, C. Aparicio, J. E. Goldberger, H. Cui, S. I. Stupp, Acta Biomater. 2012, 8, 2456-2465; b) J. D. Hartgerink, E. Beniash, S. I. Stupp, Science 2001, 294, 1684-1688; c) M. Gungormus, M. Branco, H. Fong, J. P. Schneider, C. Tamerler, M. Sarikaya, Biomaterials 2010, 31, 72667274; d) S. Hosseini, H. Naderi-Manesh, D. Mountassif, M. Cerruti, H. Vali, S. Faghihi, J. Biol. Chem. 2013, 288, 7885-7893.

[7] A. George, L. Bannon, B. Sabsay, J. W. Dillon, J. Malone, A. Veis, N. A. Jenkins, D. J. Gilbert, N. G. Copeland, J. Biol. Chem. 1996, 271, 3286932873.

[8] a) H. Cui, M. J. Webber, S. I. Stupp, Pept. Sci. 2010, 94, 1-18; b) S. Toksoz, H. Acar, M. O. Guler, Soft Matter 2010, 6, 5839-5849.

[9] a) H. Ceylan, S. Kocabey, H. Unal Gulsuner, O. S. Balcik, M. O. Guler, A. B. Tekinay, Biomacromolecules 2014, 15, 2407-2418; b) A. E. Topal, G. Tansik, A. D. Ozkan, M. O. Guler, A. Dana, A. B. Tekinay, Adv. Mater. Interfaces 2017, 4, 1700090-n/a.

[10] a) L. Addadi, S. Weiner, Angew. Chem. Int. Ed. Engl. 1992, 31, 153-169; b) S. Weiner, L. Addadi, J. Mater. Chem. 1997, 7, 689-702; c) G. K. Hunter, H. A. Goldberg, Biochem. J. 1994, 302, 175-179.

[11] a) J. D. Hartgerink, E. Beniash, S. I. Stupp, Proc. Natl. Acad. Sci. USA 2002, 99, 5133-5138; b) S. E. Paramonov, H.-W. Jun, J. D. Hartgerink, J. Am. Chem. Soc. 2006, 128, 7291-7298; c) Y. S. Dagdas, A. Tombuloglu, A. B. 
Tekinay, A. Dana, M. O. Guler, Soft Matter 2011, 7, 3524-3532; d) J. C. Stendahl, M. S. Rao, M. O. Guler, S. I. Stupp, Adv. Funct. Mater. 2006, 16, 499-508.

[12] M. A. Greenfield, J. R. Hoffman, M. Olvera de la Cruz, S. I. Stupp, Langmuir 2009, 26, 3641-3647.

[13] a) E. D. Spoerke, S. G. Anthony, S. I. Stupp, Adv. Mater. 2009, 21, 425430; b) W. J. Habraken, J. Tao, L. J. Brylka, H. Friedrich, L. Bertinetti, A. S. Schenk, A. Verch, V. Dmitrovic, P. H. Bomans, P. M. Frederik, Nat. Commun. 2013, 4, 1507; c) X. Yang, B. Xie, L. Wang, Y. Qin, Z. J. Henneman, G. H. Nancollas, CrystEngComm 2011, 13, 1153-1158.

[14] a) Y.-R. V. Shih, Y. Hwang, A. Phadke, H. Kang, N. S. Hwang, E. J. Caro, S. Nguyen, M. Siu, E. A. Theodorakis, N. C. Gianneschi, Proc. Natl. Acad. Sci. USA 2014, 111, 990-995; b) M. Mastrogiacomo, S. Scaglione, R. Martinetti, L. Dolcini, F. Beltrame, R. Cancedda, R. Quarto, Biomaterials 2006, 27, 3230-3237.

[15] a) C.-J. Liao, F.-H. Lin, K.-S. Chen, J.-S. Sun, Biomaterials 1999, 20, 18071813; b) X. Fenglan, L. Yubao, W. Xuejiang, W. Jie, Y. Aiping, J. Mater. Sci. 2004, 39, 5669-5672; c) Y. Zhai, F. Cui, J. Cryst. Growth. 2006, 291, 202206; d) Y. Ha, J. Yang, F. Tao, Q. Wu, Y. Song, H. Wang, X. Zhang, P. Yang, Adv. Funct. Mater. 2017, 1704476.

[16] G. E. Fantner, T. Hassenkam, J. H. Kindt, J. C. Weaver, H. Birkedal, L. Pechenik, J. A. Cutroni, G. A. Cidade, G. D. Stucky, D. E. Morse, Nat. Mater. 2005, 4, 612.
[17] E. Czekanska, M. Stoddart, R. Richards, J. Hayes, Eur. Cells Mater. 2012, 24, 1-17.

[18] M. Marzia, N. A. Sims, S. Voit, S. Migliaccio, A. Taranta, S. Bernardini, T. Faraggiana, T. Yoneda, G. R. Mundy, B. F. Boyce, J. Cell Biol. 2000, 151, 311-320.

[19] H. Orimo, J. Nippon Med. Sch. 2010, 77, 4-12.

[20] L. Gilbert, X. He, P. Farmer, J. Rubin, H. Drissi, A. J. Van Wijnen, J. B. Lian, G. S. Stein, M. S. Nanes, J. Biol. Chem. 2002, 277, 2695-2701.

[21] E. Birmingham, G. Niebur, P. McHugh, G. Shaw, F. Barry, L. McNamara, Eur. Cells Mater. 2012, 23, 13.

[22] a) A. Phadke, Y. R. V. Shih, S. Varghese, Macromol. Biosci. 2012, 12, 1022 1032; b) B. Marelli, C. E. Ghezzi, D. Mohn, W. J. Stark, J. E. Barralet, A. R. Boccaccini, S. N. Nazhat, Biomaterials 2011, 32, 8915-8926.

[23] a) Y. R. V. Shih, K. F. Tseng, H. Y. Lai, C. H. Lin, O. K. Lee, J. Bone Miner. Res. 2011, 26, 730-738; b) J.-H. Hwang, M. R. Byun, A. R. Kim, K. M. Kim, H. J. Cho, Y. H. Lee, J. Kim, M. G. Jeong, E. S. Hwang, J.-H. Hong, PLoS One 2015, 10, e0135519.

[24] T. D. Schmittgen, K. J. Livak, Nat. Protoc. 2008, 3, 1101-1108.

Manuscript received: November 23, 2017

Version of record online: January 18, 2018 